Louisiana State University

LSU Digital Commons

Faculty Publications

Department of Physics \& Astronomy

5-7-2013

\title{
Large magnetocaloric effects over a wide temperature range in MnCo 1-xZnxGe
}

\author{
Tapas Samanta \\ Southern Illinois University Carbondale \\ Igor Dubenko \\ Southern Illinois University Carbondale \\ Abdiel Quetz \\ Southern Illinois University Carbondale \\ Shane Stadler \\ Louisiana State University \\ Naushad Ali \\ Southern Illinois University Carbondale
}

Follow this and additional works at: https://digitalcommons.Isu.edu/physics_astronomy_pubs

\section{Recommended Citation}

Samanta, T., Dubenko, I., Quetz, A., Stadler, S., \& Ali, N. (2013). Large magnetocaloric effects over a wide temperature range in MnCo 1-xZnxGe. Journal of Applied Physics, 113 (17) https://doi.org/10.1063/ 1.4798339

This Conference Proceeding is brought to you for free and open access by the Department of Physics \& Astronomy at LSU Digital Commons. It has been accepted for inclusion in Faculty Publications by an authorized administrator of LSU Digital Commons. For more information, please contact ir@lsu.edu. 


\section{Southern Illinois University Carbondale OpenSIUC}

$5-2013$

\section{Large Magnetocaloric Effects over a Wide Temperature Range in $\mathrm{MnCo}_{1-\mathrm{x}} \mathrm{Zn}_{\mathrm{x}} \mathrm{Ge}$}

Tampas Samanta

Southern Illinois University Carbondale

Igor Dubenko

Southern Illinois University Carbondale

Abdiel Quetz

Southern Illinois University Carbondale

Shane Stadler

Louisiana State University

Naushad Ali

Southern Illinois University Carbondale

Follow this and additional works at: http://opensiuc.lib.siu.edu/phys_pubs

(C) 2013 American Institute of Physics

Published in Journal of Applied Physics Vol. 113 No. 17A922 (2013) at doi: 10.1063/1.4798339

\section{Recommended Citation}

Samanta, Tampas, Dubenko, Igor, Quetz, Abdiel, Stadler, Shane and Ali, Naushad. "Large Magnetocaloric Effects over a Wide Temperature Range in $\mathrm{MnCo}_{1-\mathrm{X}} \mathrm{Zn}_{\mathrm{x}} \mathrm{Ge}$." (May 2013).

This Article is brought to you for free and open access by the Department of Physics at OpenSIUC. It has been accepted for inclusion in Publications by an authorized administrator of OpenSIUC. For more information, please contact opensiuc@lib.siu.edu. 


\title{
Large magnetocaloric effects over a wide temperature range in $\mathrm{MnCo}_{1-\mathrm{x}} \mathrm{Zn}_{\mathbf{x}} \mathrm{Ge}$
}

\author{
Tapas Samanta, ${ }^{1, a)}$ Igor Dubenko, ${ }^{1}$ Abdiel Quetz, ${ }^{1}$ Shane Stadler, ${ }^{2}$ and Naushad Ili $^{1}$ \\ ${ }^{1}$ Southern Illinois University, Carbondale, Illinois 62901, USA \\ ${ }^{2}$ Department of Physics \& Astronomy, Louisiana State University, Baton Rouge, Louisiana 70803, USA
}

(Presented 15 January 2013; received 30 October 2012; accepted 28 December 2012; published online 27 March 2013)

\begin{abstract}
The magnetic and structural transitions can be controlled to coincide by partial substitution of $\mathrm{Zn}$ for $\mathrm{Co}$ in $\mathrm{MnCo}_{1-\mathrm{x}} \mathrm{Zn}_{\mathrm{x}} \mathrm{Ge}$, leading to a large magnetocaloric effects over a wide temperature range. The magnetostructural transition from paramagnetic to ferromagnetic state results in magnetic entropy changes $\left(-\Delta \mathrm{S}_{\mathrm{M}}\right)$ of $26 \mathrm{~J} / \mathrm{kg} \mathrm{K}$ at $327 \mathrm{~K}$ for $\Delta \mathrm{H}=5 \mathrm{~T}$ in the case of $\mathrm{x}=0.045$. Interestingly, a structurally driven first-order phase transition between two high magnetization states as observed for $\mathrm{x}=0.05$ and 0.06 also lead to large values of $-\Delta \mathrm{S}_{\mathrm{M}}=31.4$ and $20.6 \mathrm{~J} / \mathrm{kg} \mathrm{K}$ for $\Delta \mathrm{H}=5 \mathrm{~T}$ at 281 and $209 \mathrm{~K}$, respectively. The observed large magnetocaloric effects with tunable phase transition temperatures make these materials promising for near room-temperature magnetic cooling applications. (C) 2013 American Institute of Physics. [http://dx.doi.org/10.1063/1.4798339]
\end{abstract}

The research focused on magnetocaloric effects (MCE) is increasing progressively because of its potential applicability in energy-efficient, eco-friendly magnetic cooling technology. ${ }^{1-8}$ In this regard, an extensive investigation is going on to find materials with large MCE. In the present study, we report a large MCE in partially Co substituted $\mathrm{MnCo}_{1-\mathrm{x}} \mathrm{Zn}_{\mathrm{x}} \mathrm{Ge}$, which has been observed over a wide temperature range around room temperature due to drastic shift of the first-order phase transition temperature with small changes in $\mathrm{Zn}$ concentration.

Stoichiometric MnCoGe with the orthorhombic TiNiSitype structure exhibits a second-order ferromagnetic (FM) transition at $\mathrm{T}_{\mathrm{C}} \sim 345 \mathrm{~K}$. In the paramagnetic (PM) state, it undergoes a martensitic structural transformation $\left(\mathrm{T}_{\mathrm{M}}\right)$ from a low-temperature orthorhombic TiNiSi-type structure to a high-temperature hexagonal $\mathrm{Ni}_{2}$ In-type structure at about $650 \mathrm{~K}$. However, lowering the $\mathrm{T}_{\mathrm{M}}$ by changing the stoichiometry, ${ }^{9,10}$ chemical composition, ${ }^{7,8,11}$ or by applying pressure, ${ }^{11,12}$ it is possible to couple the magnetic and structural transitions. Previous studies of MnCoGe based systems indicate that the simultaneous magnetic and structural transitions occur in relative narrow temperature range for particular matching of $T_{C}$ and $T_{M}{ }^{7}$ Larger reduction of $T_{M}$ w.r.t. $T_{C}$ of $\mathrm{Ni}_{2}$ In-type structure results in decoupling of magnetic and structural phase transitions. However, if $T_{M}$ is situated just below or at the edge of the $T_{C}$ as expected for broad magnetic phase transition, the magnetic and structural changes can coincide and the corresponding first-order phase transition is dominated by crystallographic transition. ${ }^{11}$ In this paper, we are reporting the experimental observation of a structurally driven first-order phase transition between two high magnetization states in $\mathrm{MnCo}_{1-\mathrm{x}} \mathrm{Zn}_{\mathrm{x}} \mathrm{Ge}$, and show that the associated MCE is comparable to that observed for a PM-FM (disorderorder) magnetostructural transition (MST).

\footnotetext{
a) Author to whom correspondence should be addressed. Electronic mail: tapas.sinp@gmail.com.
}

The polycrystalline samples were prepared by arcmelting the constituent elements of purity better than $99.99 \%$ in an argon atmosphere. The arc-melted samples were further annealed in high vacuum $\left(\approx 10^{-5}\right.$ Torr $)$ for 4 days at $850{ }^{\circ} \mathrm{C}$. To determine the crystal structure of the samples, the X-ray diffraction (XRD) measurements were performed using $\mathrm{Cu} K \alpha$ radiation. A superconducting quantum interference device (SQUID) magnetometer was employed to measure the magnetization of $\mathrm{MnCo}_{1-\mathrm{x}} \mathrm{Zn}_{\mathrm{x}} \mathrm{Ge}$ in the temperature interval $(10-380 \mathrm{~K})$, and in applied magnetic fields up to $5 \mathrm{~T}$. The differential scanning calorimetry (DSC) measurements from 123 to $473 \mathrm{~K}$ were carried out using a DSC 8000 (with the ramp rate of $20 \mathrm{~K} / \mathrm{min}$ during heating and cooling). An estimation of the latent heat $(\mathrm{L})$ was made from the measured endothermic peak of the heat flow curve during the heating cycle of the DSC measurement using

$$
L=\int_{T_{s}}^{T_{f}} \frac{d Q}{d T} d T,
$$

where $\frac{d Q}{d T}$ is the change of heat flow with respect to temperature, $T_{s}$ and $T_{f}$ are, respectively, the starting and finishing temperatures of the first-order transition upon heating.

The room temperature XRD patterns of $\mathrm{MnCo}_{1-\mathrm{x}} \mathrm{Zn}_{\mathrm{x}} \mathrm{Ge}$ are shown in Fig. 1. For lower concentration of $\mathrm{Zn}$, $\mathrm{x}=0.045$, the system predominantly crystallizes in the orthorhombic martensitic TiNiSi-type structure with very small traces of the hexagonal phase. With a further increase of $\mathrm{Zn}$ concentrations, the hexagonal $\mathrm{Ni}_{2}$ In-type structure starts to stabilize at lower temperature. For $\mathrm{x}=0.06$ and 0.07 , the single-phase hexagonal $\mathrm{Ni}_{2} \mathrm{In}$-type structure have been detected at room temperature. It has been found in the literature that smaller Co-Co separation in $\mathrm{MnCoGe}$-based system prefer to be stabilized in the orthorhombic phase, and as a result, the distance between Co atoms is increased by inducing Co vacancies in the system, or substituting Co by a larger element can stabilize the hexagonal phase at relatively lower temperature. ${ }^{10,13}$ Therefore, the substitution of Co by 


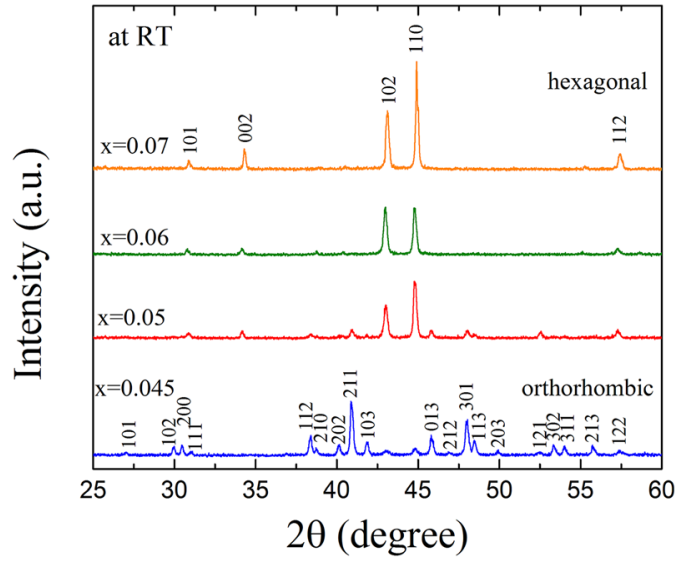

FIG. 1. XRD patterns of $\mathrm{MnCo}_{1-\mathrm{x}} \mathrm{Zn}_{\mathrm{x}} \mathrm{Ge}$ measured at room temperature.

larger $\mathrm{Zn}$ atoms $\left(\mathrm{R}_{\mathrm{Co}} \sim 0.1252 \mathrm{~nm} \text { and } \mathrm{R}_{\mathrm{Zn}} \sim 0.1394 \mathrm{~nm}\right)^{14}$ can stabilize the hexagonal $\mathrm{Ni}_{2}$ In-type structure at relatively lower temperature with increasing $\mathrm{Zn}$ concentration.

The thermomagnetization curves, $\mathrm{M}(\mathrm{T})$, during heating and cooling cycles for $\mathrm{MnCo}_{1-\mathrm{x}} \mathrm{Zn}_{\mathrm{x}} \mathrm{Ge}$ are plotted in Fig. $2(\mathrm{a})$, as measured in the presence of $0.1 \mathrm{~T}$ magnetic field. For lower $\mathrm{Zn}$ concentration, a single step-like magnetic transition with a temperature hysteresis typical for a first-order MST from a PM Ni $\mathrm{Ni}_{2}$-type structure to a FM TiNiSi-type structure has been observed for $\mathrm{x}=0.045$. Two-step phase transitions have appeared in the $\mathrm{M}(\mathrm{T})$ curves for $\mathrm{x}=0.05$ and 0.06 . The
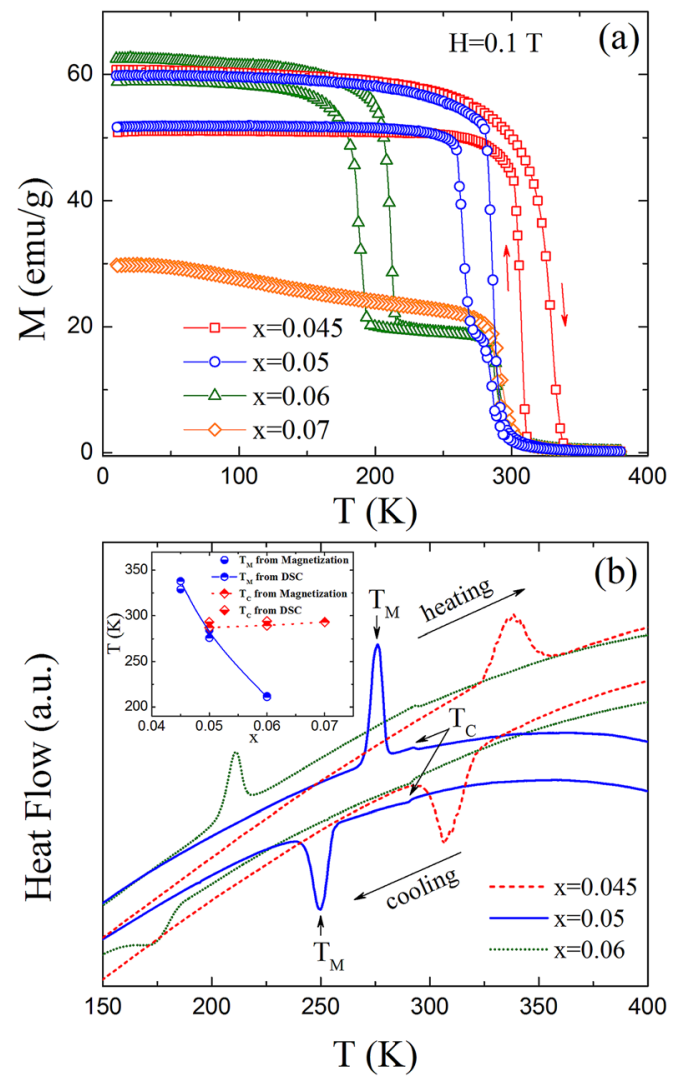

FIG. 2. (a) Temperature dependence of the magnetization $[\mathrm{M}(\mathrm{T})]$ measured during heating and cooling under the application of $0.1 \mathrm{~T}$ magnetic field. (b) DSC heat flow curves as a function of temperature measured at a rate of $20 \mathrm{~K} / \mathrm{min}$. The maxima and minima indicate the endothermic and exothermic behaviors during heating and cooling cycles, respectively. Inset: The transition temperatures as a function of $\mathrm{Zn}$ concentration. part of transition is second-order character and the remaining lower temperature part is associated with a structurally driven first-order phase transition between two high magnetization states due to the coincidence of martensitic transformation with magnetic changes below the second-order magnetic phase transition. The nature of $\mathrm{M}(\mathrm{T})$ curve during heating for $\mathrm{x}=0.05$ apparently appears as single first-order FM-PM MST. However, careful observation of $\mathrm{M}(\mathrm{T})$ curve during cooling as well as the observed two narrowly spaced peaks in DSC heat flow curve (as shown in Fig. 2(b)) clearly indicate that the part of the transition is second-order character followed by a first-order transition at lower temperature for $\mathrm{x}=0.05$. For $\mathrm{x}=0.07$, a second-order magnetic transition similar to that observed for the PM-FM transition with the hexagonal $\mathrm{Ni}_{2} \mathrm{In}$-type structure has been detected with no signature of first-order transition. The variation of transition temperatures with $\mathrm{Zn}$ concentration is shown in inset of Fig. 2(b). It has been found that a small variation in the $\mathrm{Zn}$ concentration from $\mathrm{x}=0.045$ to $\mathrm{x}=0.060$ results in a large shift of $\mathrm{T}_{\mathrm{M}}$ from $\sim 329$ to $212 \mathrm{~K}$, as determined from the maximum change of the temperature dependent $\mathrm{dM} / \mathrm{dT}$ curves and considering the peak position of DSC heat flow curve (as shown in Fig. 2(b)). The observed large endothermic/exothermic peaks during heating/cooling cycles in DSC heat flow curves, accompanied by the latent heat, as well as the clearly visible thermal hysteresis between heating and cooling cycles, indicate the first-order nature of the phase transition.

The isothermal magnetic entropy change $\left(-\Delta S_{M}\right)$ as a function of temperature for $\mathrm{MnCo}_{1-\mathrm{x}} \mathrm{Zn}_{\mathrm{x}} \mathrm{Ge}$ is plotted in Fig. 3(a). Employing a Maxwell relation, $\Delta S_{M}=\int_{0}^{H}\left(\frac{\partial M}{\partial T}\right)_{H} d H$, the value of $-\Delta S_{M}$ was estimated taking the isothermal magnetization curves as measured at different constant
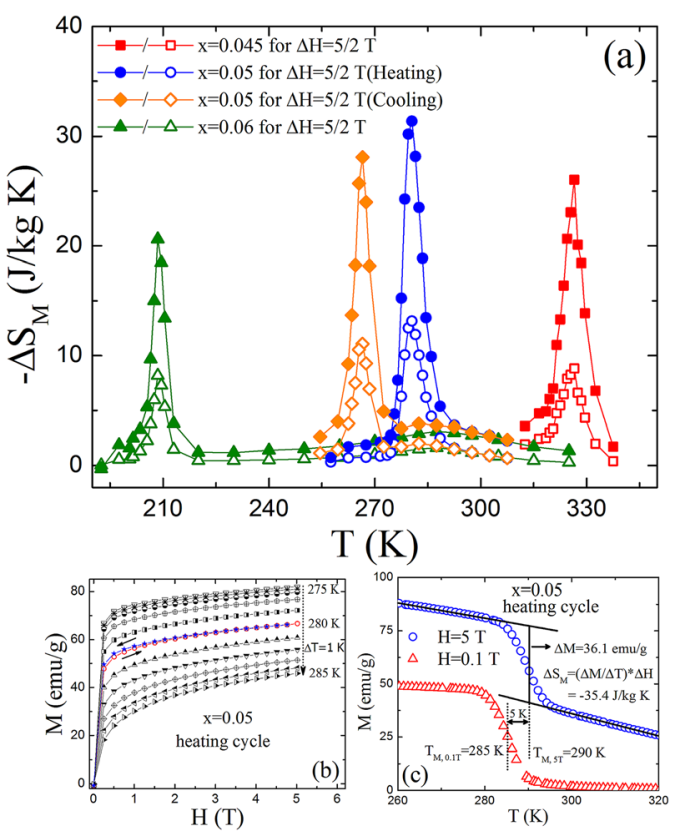

FIG. 3. (a) Plot of the magnetic entropy changes $\left(-\Delta \mathrm{S}_{\mathrm{M}}\right)$ as a function of temperature for different magnetic field changes of $\Delta \mathrm{H}=5$ (solid symbols) and $2 \mathrm{~T}$ (open symbols), respectively. (b) The isothermal magnetization measured during heating in the vicinity of $T_{M}$ for $x=0.05$. (c) Heating thermomagnetization curves for applied fields $\mathrm{H}=0.1$ and $5 \mathrm{~T}$, respectively, to estimate the value of $-\Delta \mathrm{S}_{\mathrm{M}}$ for $\mathrm{x}=0.05$ using Clausius-Clapeyron equation. 
TABLE I. Type of phase transitions, Curie temperatures $\left(\mathrm{T}_{\mathrm{C}}\right.$ ), and maximum $-\Delta \mathrm{S}_{\mathrm{M}}$ for different materials including $\mathrm{MnCo}_{1-\mathrm{x}} \mathrm{Zn}_{\mathrm{x}} \mathrm{Ge}$ (present work) for a field change of $5 \mathrm{~T}$.

\begin{tabular}{|c|c|c|c|c|c|}
\hline Material & Type of phase transitions & $\mathrm{T}_{\mathrm{C}}(\mathrm{K})$ & $\mathrm{T}_{\mathrm{M}}(\mathrm{K})$ & $-\Delta \mathrm{S}_{\mathrm{M}}(\mathrm{J} / \mathrm{kg} \mathrm{K})$ & References \\
\hline $\mathrm{MnCo}_{1-\mathrm{x}} \mathrm{Zn}_{\mathrm{x}} \mathrm{Ge}$ & & & & & Present work \\
\hline$x=0.045$ & MST PM-FM & 329 & & 26 & \\
\hline \multirow{2}{*}{$x=0.05$} & Structurally driven first-order & 293 & 285 & 31.4 , heating & \\
\hline & & 293 & 265 & 28.1, cooling & \\
\hline$x=0.06$ & Structurally driven first-order & 294 & 211 & 20.6 & \\
\hline $\mathrm{MnCoGeB}_{\mathrm{x}}$ & & & & & 7 \\
\hline$x=0.01$ & MST PM-FM & 304 & & 14.6 & \\
\hline$x=0.02$ & MST PM-FM & 287 & & 47.3 & \\
\hline$x=0.03$ & MST PM-FM & 275 & & 37.7 & \\
\hline$x=0.05$ & Second-order PM-FM & 260 & & 3.4 & \\
\hline $\mathrm{Mn}_{1-\mathrm{x}} \mathrm{Cr}_{\mathrm{x}} \mathrm{CoGe}$ & & & & & 8 \\
\hline$x=0.04$ & MST PM-FM & 322 & & 28.5 & \\
\hline$x=0.11$ & MST PM-FM & 292 & & 27.7 & \\
\hline$x=0.18$ & MST PM-FM & 274 & & 15.6 & \\
\hline$x=0.25$ & MST PM-FM & 237 & & 12.3 & \\
\hline $\mathrm{Gd}_{5} \mathrm{Si}_{2} \mathrm{Ge}_{2}$ & MST PM-FM & 277 & & 18 & 15 \\
\hline $\mathrm{MnFeP}_{0.45} \mathrm{As}_{0.55}$ & MST PM-FM & 305 & & 18 & 3 \\
\hline
\end{tabular}

temperatures. A representative figure of $\mathrm{M}(\mathrm{H})$ curves as measured during heating for $\mathrm{x}=0.05$ is shown in Fig. 2(b). Almost negligible magnetic hysteresis has been detected in the vicinity of $\mathrm{T}_{\mathrm{M}}(\mathrm{T}=280 \mathrm{~K})$. Large positive values of $-\Delta S_{M}$ have been observed for $\mathrm{MnCo}_{1-\mathrm{x}} \mathrm{Zn}_{\mathrm{X}} \mathrm{Ge}$ in the vicinity of $\mathrm{T}_{\mathrm{M}}$. The estimated $-\Delta \mathrm{S}_{\mathrm{M}}$ under a magnetic field change of $\Delta \mathrm{H}=5 \mathrm{~T}$ reaches a value of $26 \mathrm{~J} / \mathrm{kg} \mathrm{K}$ in the vicinity of $\mathrm{T}_{\mathrm{M}} \sim 327 \mathrm{~K}$ for $\mathrm{x}=0.045$, due to a single PM-FM (disorder-order) MST. Interestingly, a structurally driven firstorder phase transition between two high magnetization states as observed for $\mathrm{x}=0.05$ and 0.06 also lead to large values of $-\Delta \mathrm{S}_{\mathrm{M}}=31.4$ and $20.6 \mathrm{~J} / \mathrm{kg} \mathrm{K}$ for $\Delta \mathrm{H}=5 \mathrm{~T}$ at 281 and $209 \mathrm{~K}$, respectively. The measured $\mathrm{M}(\mathrm{H})$ curves during cooling cycle results in a relatively lower but large enough value of $-\Delta \mathrm{S}_{\mathrm{M}}=28.1 \mathrm{~J} / \mathrm{kg} \mathrm{K}$ as observed at $266 \mathrm{~K}$ for $\mathrm{x}=0.05$. The values of $-\Delta S_{M}$ for $x=0.05$ as estimated from ClausiusClapeyron equation were found out to be 35.4 and $33.5 \mathrm{~J} / \mathrm{kg} \mathrm{K}$ for $\Delta \mathrm{H}=5 \mathrm{~T}$ during heating and cooling cycles, respectively [where, $\Delta \mathrm{M}=36.1,34.2 \mathrm{emu} / \mathrm{g}$ and $\Delta \mathrm{T}=5,5 \mathrm{~K}$ during heating and cooling, respectively], which were calculated from thermomagnetization curves measured at different constant magnetic fields (see Fig. 3(c)). Previous studies on MnCoGebased systems indicate that a structurally driven first-order phase transition due to coincidence of magnetic and crystallographic changes can result in a relatively lower value of MCE. ${ }^{11}$ However, the observed values of $-\Delta S_{M}$ due to structurally driven first-order phase transition between two high magnetization states for $\mathrm{x}=0.05$ and 0.06 are comparable with other reported $\mathrm{MnCoGe-based} \mathrm{systems}{ }^{7,8,11}$ including well-known giant MCE materials, such as $\mathrm{Gd}_{5} \mathrm{Si}_{2} \mathrm{Ge}_{2}$ (Ref. 15) and $\mathrm{MnFeP}_{0.45} \mathrm{As}_{0.55}$ (Ref. 3) exhibiting single PM-FM MST, which is summarized in Table I. Moreover, the total entropy changes, $-\Delta \mathrm{S}_{\mathrm{T}}$, as estimated from DSC heating curves, were found out to be 33.1, 39, and 22.8 $\mathrm{J} / \mathrm{kg} \mathrm{K}$, corresponding to the associated latent heat, $\mathrm{L}=-11.2$, -10.66 , and $-4.81 \mathrm{~J} / \mathrm{g}$ for $\mathrm{x}=0.045,0.050$, and 0.060 , respectively. Interestingly, the values of $-\Delta \mathrm{S}_{\mathrm{T}}$ associated with a structurally driven first-order phase transition between two high magnetization states for $\mathrm{x}=0.05$ and 0.06 , respectively, are even larger and comparable than some giant MCE materials exhibiting PM-FM MST's, such as single crystalline $\mathrm{Ni}_{55} \mathrm{Mn}_{20} \mathrm{Ga}_{25}\left(-\Delta \mathrm{S}_{\mathrm{T}}=24 \mathrm{~J} / \mathrm{kg} \mathrm{K}\right.$ as estimated from latent heat). ${ }^{16}$ Therefore, the exhibition of large, compositiondependent $-\Delta \mathrm{S}_{\mathrm{M}}$ over a wide temperature range makes the $\mathrm{MnCo}_{1-\mathrm{x}} \mathrm{Zn}_{\mathrm{x}} \mathrm{Ge}$ system a promising magnetic refrigerant for magnetic cooling technology that can be effective from well above room temperature down to approximately $209 \mathrm{~K}$.

In summary, it has been found from our experimental study that not only the paramagnetic-ferromagnetic (disorder-order) magnetostructural transition but also the structurally driven first-order phase transition between two high magnetization states can lead to a large MCE. As a result, large composition dependent magnetocaloric effects have been observed over a wide temperature range near room temperature in $\mathrm{MnCo}_{1-\mathrm{x}} \mathrm{Zn}_{\mathrm{x}} \mathrm{Ge}$, which make these materials promising for magnetic refrigeration.

This work was supported by the Office of Basic Energy Sciences, Material Science Division of the U.S. Department of Energy (Grant No. DE-FG02-06ER46291).

\footnotetext{
${ }^{1}$ V. K. Pecharsky and K. A. Gschneidner, Jr., Phys. Rev. Lett. 78, 4494 (1997).

${ }^{2}$ J. Liu et al., Nature Mater. 11, 620 (2012).

${ }^{3}$ O. Tegus et al., Nature (London) 415, 150 (2002).

${ }^{4}$ T. Krenke et al., Nature Mater. 4, 450 (2005).

${ }^{5}$ T. Samanta et al., Appl. Phys. Lett. 91, 152506 (2007).

${ }^{6}$ I. Dubenko et al., J. Magn. Magn. Mater. 321, 754 (2009).

${ }^{7}$ N. T. Trung et al., Appl. Phys. Lett. 96, 172504 (2010).

${ }^{8}$ N. T. Trung et al., Appl. Phys. Lett. 96, 162507 (2010).

${ }^{9}$ T. Kanomata et al., J. Magn. Magn. Mater. 140-144, 131 (1995).

${ }^{10}$ J. T. Wang et al., Appl. Phys. Lett. 89, 262504 (2006).

${ }^{11}$ L. Caron et al., Phys. Rev. B 84, 020414(R) (2011).

${ }^{12}$ S. Niziol et al., J. Magn. Magn. Mater. 79, 333 (1989).

${ }^{13}$ W. Zhang et al., J. Mater. Sci. Technol. 25, 781 (2009).

${ }^{14} \mathrm{~W}$. B. Pearson, The Crystal Chemistry and Physics of Metals and Alloys (Wiley-Interscience, New York, 1972).

${ }^{15}$ A. O. Pecharsky et al., J. Appl. Phys. 93, 4722 (2003).

${ }^{16}$ M. Pasquale et al., Phys. Rev. B 72, 094435 (2005).
} 